\title{
EVALUASI KETERSEDIAAN DAYA PADA PT. PLN (PERSERO) GARDU INDUK BUNGARAN PALEMBANG
}

\author{
Abdul Azis ${ }^{1,}$ Irine Kartika Febrianti ${ }^{2}$ \\ ${ }^{1,2}$ Program Studi Teknik Elektro, Fakultas Teknik, Universitas PGRI Palembang \\ email: azis@univpgri-palembang.ac.id
}

\begin{abstract}
Abstrak - Rugi-rugi daya adalah kehilangan daya listrik di jaringan dan beban dimana daya yang hilang tersebut tidak terpakai oleh beban, sehingga daya yang tersedia di jaringan akan berkurang. Rugi-rugi daya pada jaringan distribusi disebabkan oleh adanya tahanan pada penghantar. Daya yang hilang dapat berupa energi panas yang ditimbulkan pada saluran, dan energi panas yang tidak terpakai disebut sebagai rugi-rugi daya aktif. Rugi-rugi daya disetiap saluran sangatlah penting untuk diperhitungkan karena rugi-rugi daya di jaringan dapat menyebabkan berkurangnya energi listrik setelah sampai di beban. Kebutuhan daya yang harus disuplai oleh sumber ke beban tergantung pada penyerapan daya oleh beban dan rugi-rugi daya di jaringan. Besar kapasitas kebutuhan daya dipengaruhi oleh besarnya rugi-rugi daya, sehingga dapat dikatakan bahwa kapasitas kebutuhan daya merupakan jumlah penyerapan daya oleh beban dan rugi-rugi daya di jaringan. Salah satu gardu induk di Kota Palembang adalah Gardu Induk Bungaran yang mempunyai fungsi menyalurkan energi listrik ke konsumen melalui sistem distribusi tegangan menengah. Untuk melayani kebutuhan energi listrik konsumen, saat ini Gardu Induk Bungaran Palembang mempunyai Transformator 1, 30 MVA 70/20 kV yang mempunyai beban empat buah penyulang, yaitu: Penyulang Akasia, Penyulang Sungkai, Penyulang Tembesu, dan Penyulang Cendana. Dari hasil penelitian diperoleh hasil bahwa Transformator 1 mempunyai kapasitas daya terpasang sebesar 30 MVA atau 255.000.000 Watt. Sedangkan kapasitas kebutuhan daya total dari empat penyulang adalah 18.786.167,4264 W. Jadi ketersediaan daya Transformator 1 masih mencukupi untuk melayani beban dari empat penyulang, karena hanya 7,3671\% dari kapasitas daya terpasang daya yang diserap oleh beban.
\end{abstract}

\section{Kata Kunci : Daya, kebutuhan dan ketersediaan}

\begin{abstract}
Power losses are the loss of electrical power in the network and the load where the lost power is not used by the load, so the power available on the network will be reduced. Power losses in the distribution network are caused by the presence of prisoners in the carrier. The lost power can be in the form of heat energy generated on the channel, and unused heat energy is called active power losses. Power losses in each channel are very important to take into account because power losses in the network can cause a reduction in electrical energy after arriving at the load. Power requirements that must be supplied by the source to the load depend on the absorption of power by the load and power losses on the network. Large capacity of power requirements is influenced by the amount of power losses, so it can be said that the capacity of power needs is the amount of absorption of power by the load and power losses on the network. One of the substations in the city of Palembang is the Bungaran Substation which has the function of delivering electrical energy to consumers through a medium voltage distribution system. To serve consumers electrical energy needs, currently the Bungaran Palembang Substation has a Transformer 1, 30 MVA 70/20 kV which has a load of four feeders, namely: Akasia Feeder, Sungkai Feeder, Tembesu Feeder, and Cendana Feeder. The results showed that Transformer 1 had an installed power capacity of 30 MVA or 255,000,000 Watts. While the capacity of the total power requirements of the four feeders is $18,786,167.4264 \mathrm{~W}$. So the availability of transformer 1 power is still sufficient to serve the load of four feeders, because only $7.3671 \%$ of the installed power capacity is absorbed by the load.
\end{abstract}

Keywords : Power, needs and availability 


\section{PENDAHULUAN}

Energi listrik sudah menjadi kebutuhan primer bagi masyarakat saat ini. Penyediaan energi listrik yang berkualitas, ekonomis dan andal menjadi isu penting bagi produsen maupun konsumen tenaga listrik. Keandalan sistem tenaga listrik menunjukkan kontinuitas penyediaan tenaga listrik yang dapat dilihat dari seberapa sering sistem tersebut mengalami gangguan. Untuk memenuhi kebutuhan energi listrik di Provinsi Sumatera Selatan saat ini total kapasitas terpasang pembangkit tenaga listrik yang terpasang sampai dengan Tahun 2015 sebesar 936,27 MW. Daya terpasang tersebut disuplai dari pembangkit tenaga listrik PLN sebesar 627,27 MW, dan pembangkit tenaga listrik non PLN sebesar 309,00 MW [1].

adalah Gardu Induk Bungaran merupakan salah satu gardu induk di Kota Palembang. Gardu Induk Bungaran Palembang mempunyai dua buah transformator dengan masing-masing kapasitas daya terpasang sebesar 30 MVA. Transformator 1, 30 MVA 70/20 kV mempunyai beban empat buah penyulang, dan Transformator 2, 30 MVA 70/20 kV mempunyai beban dua buah penyulang. Penelitian hanya dilakukan pada Transformator 1 yang mempunyai beban empat buah penyulang, yaitu: Penyulang Akasia, Penyulang Sungkai, Penyulang Tembesu, dan Penyulang Cendana. Adapun tujuan dari penelitian ini adalah untuk mengetahui besar rugi-rugi daya dan kapasitas kebutuhan daya pada jaringan distribusi primer $20 \mathrm{kV}$, serta mengevaluasi ketersediaan daya di Gardu Induk Bungaran Palembang. Untuk perhitungan rugi-rugi daya dan kapasitas kebutuhan daya pada jaringan distribusi, ditinjau pada saat beban puncak dan beban diasumsikan dalam keadaan seimbang.

Kebutuhan daya listrik yang harus disuplai oleh Gardu Induk Bungaran Palembang ke konsumen tergantung pada besarnya penyerapan daya oleh beban dan rugi-rugi daya di jaringan distribusi tegangan menengah. Besarnya rugi-rugi daya di jaringan distribusi tegangan menengah dipengaruhi oleh besar beban yang dilayani, panjang sistem penyaluran energi listrik itu sendiri, besar kecilnya luas penampang penghantar yang digunakan, dan jenis penghantar yang digunakan. Besarnya kebutuhan daya listrik tentunya akan mempengaruhi ketersediaan daya listrik pada Gardu Induk Bungaran Palembang.

\section{TINJAUAN PUSTAKA}

\section{Jaringan Distribusi Radial}

Di dalam sistem jaringan distribusi tegangan menengah tipe radial hanya terdiri dari satu jaringan utama dan beberapa buah segmen cabang. Jaringan distribusi yang keluar dari pembangkit dapat dibedakan menjadi [2]: Penyulang Utama (Main Feeder), Penyulang Cabang (Lateral Feeder), Penyulang Sub-Cabang (Sub-Lateral Feeder). 


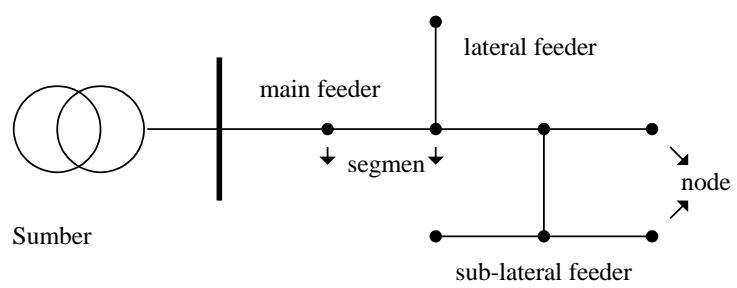

Gambar 1. Struktur jaringan distribusi tipe radial

Kelemahan Sistem jaringan tipe radial [2] hanya dihubungkan pada satu sumber daya melalui satu jalan, maka kelangsungan pelayanannya kurang terjamin. Apabila terjadi gangguan pada feeder utama yang paling dekat dengan sumber daya maka akan terjadi pemutusan seluruh pelayanan sampai gangguan tersebut dapat diatasi dan untuk mempertinggi keandalan sistem dibuat beberapa modifikasi sistem, seperti:

1. Sistem jaringan distribusi tipe radial dengan jaringan penghubung

Untuk daerah beban yang berdampingan dapat saling berhubungan melalui suatu jaringan penghubung. Pada sistem distribusi yang menggunakan jaringan penghubung, kapasitasnya harus direncanakan sedemikian rupa sehingga dapat menggantikan jaringan yang terganggu tanpa mengganggu fungsi yang sebenarnya. Jaringan penghubung dipasang di antara dua buah feeder yang berdampingan pada tempat-tempat sepanjang feeder. Alat-alat pemutus dipasang pada beberapa tempat feeder untuk mengisolasi gangguan.

2. Sistem jaringan distribusi tipe radial dengan feeder ekspres pusat beban

Jaringan distrbusi primer bentuk ini memiliki pembagian yang tidak dimulai dari sumber daya atau gardu induk, tetapi dimulai dari pusat beban. Sistem ini memiliki feeder ekspres dimana di sepanjang feeder ekspres ini tidak terdapat transformator distribusi atau beban lainnya. Dari pusat beban ini keluar cabang- cabang, umumnya empat cabang atau empat arah. Keuntungan dari sistem ini adalah dapat mengurangi jatuh tegangan antara beban terdekat dan beban terjauh dibandingkan dengan jatuh tegangan pada sistem radial yang sederhana. Dengan regulasi yang sama dan pemakaian konduktor pada lateral dan sublateral yang sama, maka sistem ini dapat melayani beban-beban yang besar.

3. Sistem Jaringan Distribusi Tipe Radial Dengan Susunan Daerah Phasa

Pada sistem ini tiap-tiap phasa dari feeder tiga phasa ditarik menuju daerah-daerah yang berlainan. Sistem pelayanannya dapat berupa sistem radial dengan feeder pusat beban. Untuk merancanakan sistem ini harus diperhatikan agar beban-bebannya seimbang. Beban tiga phasa tidak diperbolehkan pada daerah beban kecuali beban tiga phasa tersebut terdapat di sepanjang feeder utama, sebelum tiap-tiap phasa tersebut dibagi ke daerah 
pelayanannya masing-masing. Pada daerah yang masih berkembang, sistem ini kurang fleksibel karena akan mengganggu keseimbangan beban antara ketiga phasa tersebut. Sistem ini cocok digunakan pada daerah-daerah yang sudah stabil dan berbeban ringan, seperti daerah perumahan.

\section{Rugi-Rugi Daya}

Rugi-rugi daya adalah kehilangan daya listrik di jaringan dan beban dimana daya yang hilang tersebut tidak terpakai oleh beban, sehingga daya yang tersedia di jaringan akan berkurang. Rugi-rugi daya pada jaringan distribusi disebabkan oleh adanya tahanan pada penghantar. Daya yang hilang dapat berupa energi panas yang ditimbulkan pada saluran, dan energi panas yang tidak terpakai disebut sebagai rugi-rugi daya aktif. Rugi-rugi daya disetiap saluran sangatlah penting untuk diperhitungkan karena rugi-rugi daya di jaringan dapat menyebabkan berkurangnya energi listrik setelah sampai di beban [8].

\section{Kapasitas Kebutuhan Daya}

Kebutuhan daya yang harus disuplai oleh sumber ke beban tergantung pada penyerapan daya oleh beban dan rugi-rugi daya di jaringan. Besar kapasitas kebutuhan daya dipengaruhi oleh besarnya rugi-rugi daya, sehingga dapat dikatakan bahwa kapasitas kebutuhan daya merupakan jumlah penyerapan daya oleh beban dan rugi-rugi daya di jaringan.

\section{METODE PENELITIAN}

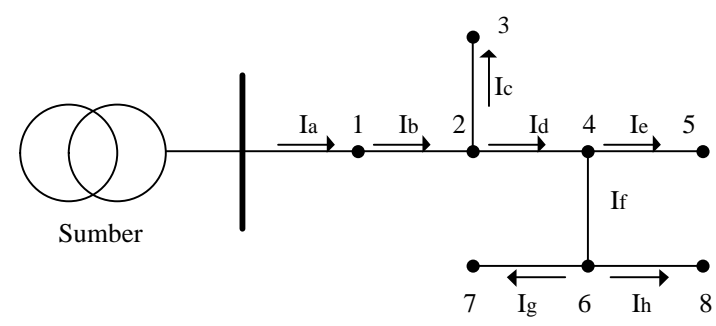

Gambar 2. Topologi Jaringan Distribusi Radial

\section{Penentuan Tahanan Segmen}

Suatu jaringan distribusi tegangan menengah mempunyai nilai tahanan yang berbedabeda. Untuk menetukan besarnya tahanan pada jaringan tersebut, maka yang perlu diketahui adalah [3]: Jenis penghantar yang digunakan pada jaringan distribusi ( $\mathrm{Al}$ atau $\mathrm{Cu}$ ), Ukuran dari diameter saluran $\left(\mathrm{mm}^{2}\right)$,Panjang saluran per segmen cabang $(\mathrm{km})$. Dengan demikian nilai tahanan persegmen cabang dapat ditentukan dengan persamaan sebagai berikut: 


$$
R_{j}=R_{j} \cdot l_{j}
$$

\section{Penentuan Arus Beban}

Untuk mendapatkan arus beban $\left(I_{i}\right)$ dari setiap node dapat dihitung dengan pendekatanpendekatan sebagai berikut [4]:

1. Tegangan minimal yang ditetapkan untuk suatu jaringan tegangan menengah adalah $0,95 \cdot V_{n}$

2. Karakteristik kurva beban untuk suatu klasifikasi beban tertentu adalah sama sehingga untuk jaringan tegangan rendah dan tranformator distribusi pada klasifikasi beban tertentu adalah sama.

3. Faktor daya untuk jaringan tegangan menengah diambil sama untuk setiap terminal beban yaitu $\cos \theta=0,85$.

Untuk jaringan tegangan menengah, arus beban $\left(I_{\text {sekunder }}\right)$ diukur pada sisi tegangan sekunder $(380 \mathrm{~V})$ tranformator distribusi, sehingga daya dari setiap node dapat ditentukan dengan persamaan sebagai berikut:

$$
P_{i}=\sqrt{3} \cdot V_{n} \cdot I_{\text {sekunder }}
$$

Berdasarkan keadaan tersebut maka arus beban sisi primer tranformator distribusi $\left(I_{i}\right)$ dari setiap node dapat ditentukan dengan persamaan sebagai berikut:

$$
I_{i}=\frac{P_{i}}{\sqrt{3} \cdot 0,95 \cdot V_{s} \cdot \cos \theta_{i}}
$$

\section{Penentuan Arus Segmen}

Untuk mendapatkan arus segmen $\left(I_{j}\right)$ dari setiap segmen jaringan distribusi dapat dilakukan dengan menjumlahkan arus beban $\left(I_{i}\right)$ dari setiap titik simpul beban atau node.

\section{Penentuan Rugi-rugi Daya Tiap Segmen}

Rugi-rugi daya per phasa dari setiap segmen $\left(\Delta P_{j}\right)$ yang disebabkan oleh adanya tahanan segmen $\left(R_{j}\right)$ dan kuadrat arus saluran $\left(I_{j}\right)$ dapat ditentukan berdasarkan persamaan (2) yaitu:

$$
\Delta P_{j(1 \text { phasa })}=\left(I_{j}\right)^{2} \cdot R_{j} \cdot l_{j}
$$

Karena penghantar jaringan distribusi adalah 3 phasa, maka:

$$
\Delta P_{j(3 \text { phasa })}=3 \cdot\left(I_{j}\right)^{2} \cdot R_{j} \cdot l_{j}
$$

\section{Penentuan Rugi-rugi Daya Total Jaringan Distribusi}


Setelah didapatkan rugi-rugi daya dari setiap segmen, maka dapat ditentukan rugi-rugi daya total pada jaringan distribusi dengan menjumlahkan rugi-rugi daya dari setiap segmen cabang, yaitu:

$$
\Delta P_{\text {total }}=\sum_{j=a}^{n} \Delta P_{j}
$$

\section{Penentuan Kapasitas Kebutuhan Daya}

Kapasitas kebutuhan daya $\left(P_{\text {total }}\right)$ merupakan jumlah dari daya total dari sumber yang diinjeksikan ke beban dengan rugi-rugi daya total pada jaringan distribusi. Besarnya kapasitas kebutuhan daya dapat ditentukan dengan menggunakan persamaan sebagai berikut:

$$
P_{\text {total }}=P_{\text {input }}+\Delta P_{\text {total }}
$$

Efisiensi penyaluran daya listrik yang merupakan perbandingan antara daya total $\left(P_{\text {input }}\right)$ dari sumber yang diinjeksikan ke beban dengan kapasitas kebutuhan daya $\left(P_{\text {total }}\right)$ pada jaringan distribusi. Besarnya efisiensi penyaluran daya listrik dapat ditentukan dengan menggunakan persamaan sebagai berikut:

$$
\eta(\%)=\frac{P_{\text {input }}}{P_{\text {total }}} \cdot 100 \%
$$

Dimana $P_{\text {input }}=\sqrt{3} \cdot V_{n} \cdot I_{a} \cdot \cos \theta$ Sehingga persentase rugi-rugi daya pada jaringan distribusi adalah:

$$
\Delta P_{\text {total }}(\%)=\frac{\Delta P_{\text {total }}}{P_{\text {total }}} \cdot 100 \%
$$

Selanjutnya dapat ditentukan persentase kapasitas kebutuhan daya yang merupakan perbandingan antara kapasitas kebutuhan daya $\left(P_{\text {total }}\right)$ dengan daya terpasang pada transformator $\left(P_{\text {tranformator }}\right)$ pada jaringan distribusi. Maka persentase kapasitas kebutuhan daya adalah:

$$
P_{\text {total }}(\%)=\frac{P_{\text {total }}}{P_{\text {tranformator }}} \cdot 100 \%
$$

\section{HASIL DAN PEMBAHASAN}

Gardu Induk Bungaran Palembang mempunyai fungsi menyalurkan energi listrik ke konsumen melalui sistem distribusi tegangan menengah. Untuk melayani kebutuhan energi listrik konsumen, saat ini Transformator 1, 30 MVA 70/20 kV Gardu Induk Bungaran Palembang mempunyai beban empat buah penyulang, yaitu: Penyulang Akasia, Penyulang Sungkai, Penyulang Tembesu, dan Penyulang Cendana. 


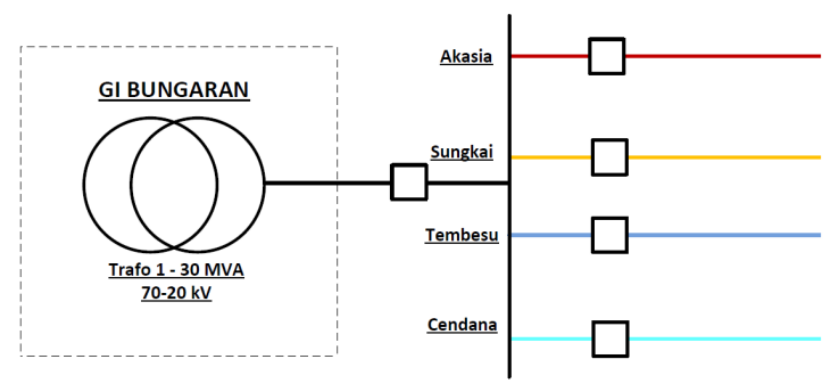

Gambar 3. Representasi Penyulang Pada Transformator 1, 30 MVA 70/20 kV Gardu Induk Bungaran Palembang

\section{Data Penyulang}

Transformator 1, 30 MVA 70/20 kV di PT PLN (Persero) Gardu Induk Bungaran Palembang mempunyai beban empat buah penyulang, yaitu: Penyulang Akasia, Penyulang Sungkai, Penyulang Tembesu, dan Penyulang Cendana.

Tabel 1. Data Teknik Penyulang

\begin{tabular}{|l|l|l|l|l|}
\hline & Penyulang Akasia & $\begin{array}{l}\text { Penyulang } \\
\text { Sungkal }\end{array}$ & $\begin{array}{l}\text { Penyulang } \\
\text { Tembesu }\end{array}$ & $\begin{array}{l}\text { Penyulang } \\
\text { Cendana }\end{array}$ \\
\hline Panjang & $9,400 \mathrm{~km}$ & $8,910 \mathrm{~km}$ & $10,160 \mathrm{~km}$ & $16,505 \mathrm{~km}$ \\
\hline $\begin{array}{l}\text { Jumlah } \\
\text { Transformator }\end{array}$ & $65 \mathrm{buah}$ & 19 buah & 16 buah & 65 buah \\
\hline Jenis Penghantar & A3C & A3C & A3C & A3C \\
\hline $\begin{array}{l}\text { Luas Penampang } \\
\text { Penghantar }\end{array}$ & $150 \mathrm{~mm}^{2}$ & $150 \mathrm{~mm}^{2}$ & $150 \mathrm{~mm}^{2}$ & $150 \mathrm{~mm}^{2}$ \\
\hline
\end{tabular}

Tabel 2. Data Beban Harian Rata-Rata Bulan Juni 2016

\begin{tabular}{|c|c|c|c|c|c|}
\hline \multirow{2}{*}{ Jam } & \multicolumn{5}{|c|}{ Arus (A) Penyulang } \\
\cline { 2 - 6 } & Akasia & Sungkai & Tembesu & Cendana & Jumlah \\
\hline 00.00 & 180 & 77 & 39 & 239 & 534 \\
\hline 01.00 & 169 & 73 & 37 & 224 & 503 \\
\hline 02.00 & 169 & 71 & 35 & 229 & 505 \\
\hline 03.00 & 165 & 69 & 35 & 225 & 494 \\
\hline 04.00 & 163 & 68 & 34 & 220 & 485 \\
\hline 05.00 & 161 & 67 & 33 & 217 & 478 \\
\hline 06.00 & 162 & 67 & 32 & 214 & 475 \\
\hline 07.00 & 173 & 66 & 30 & 214 & 484 \\
\hline 08.00 & 185 & 66 & 31 & 213 & 494 \\
\hline 09.00 & 200 & 67 & 33 & 217 & 517 \\
\hline 10.00 & 199 & 64 & 33 & 225 & 521 \\
\hline 11.00 & 205 & 69 & 34 & 235 & 543 \\
\hline 12.00 & 207 & 70 & 36 & 245 & 557 \\
\hline 13.00 & 219 & 74 & 37 & 254 & 584 \\
\hline 14.00 & 216 & 75 & 37 & 251 & 579 \\
\hline 15.00 & 220 & 75 & 37 & 246 & 578 \\
\hline 16.00 & 201 & 71 & 36 & 239 & 546 \\
\hline 17.00 & 195 & 73 & 36 & 243 & 547 \\
\hline 18.00 & 201 & 79 & 37 & 256 & 574 \\
\hline 18.30 & 205 & 88 & 42 & 288 & 624 \\
\hline
\end{tabular}




\begin{tabular}{|c|c|c|c|c|c|}
\hline 19.00 & 209 & 88 & 42 & 294 & 633 \\
\hline 19.30 & 207 & 88 & 42 & 294 & 631 \\
\hline 20.00 & 203 & 87 & 42 & 293 & 625 \\
\hline 21.00 & 196 & 82 & 41 & 278 & 597 \\
\hline 22.00 & 184 & 80 & 40 & 268 & 571 \\
\hline 23.00 & 166 & 75 & 37 & 246 & 525 \\
\hline 24.00 & 149 & 70 & 34 & 234 & 488 \\
\hline Rata-Rata & 189 & 74 & 36 & 244 & 544 \\
\hline
\end{tabular}

Sumber: Pengolahan data

Tabel 3. Hasil Perhitungan Rugi-Rugi Daya Dan Kapasitas Kebutuhan Daya Penyulang

\begin{tabular}{|l|r|c|c|c|c|c|}
\hline \multirow{2}{*}{ Penyulang } & \multicolumn{2}{|c|}{$\begin{array}{c}\text { Rugi-Rugi Daya } \\
(\Delta \mathrm{P})\end{array}$} & \multicolumn{2}{c|}{$\begin{array}{c}\text { Penyaluran Daya } \\
\text { Ke Beban }\left(\mathrm{P}_{\text {input }}\right)\end{array}$} & \multicolumn{2}{c|}{$\begin{array}{c}\text { Kapasitas Kebutuhan Daya } \\
\left(\mathrm{P}_{\text {total }}\right)\end{array}$} \\
\cline { 2 - 7 } & $($ Watt $)$ & $(\%)$ & Watt & $(\%)$ & Watt & $(\%)$ \\
\hline Akasia & $35.046,1565$ & 0,5654 & $6.162 .888,4627$ & 99,4313 & $6.197 .934,6192$ & 2,4306 \\
\hline Sungkai & $10.120,2189$ & 0,3889 & $2.591 .907,1018$ & 99,6095 & $2.602 .027,3207$ & 1,0204 \\
\hline Tembesu & $3.328,8957$ & 0,2684 & $1.236 .961,8250$ & 99,7309 & $1.240 .290,7207$ & 0,4864 \\
\hline Cendana & $88.204,2855$ & 1,0085 & $8.657 .710,4804$ & 98,9812 & $8.745 .914,7658$ & 3,4298 \\
\hline Jumlah & $136.699,5566$ & 0,7277 & $18.649 .467,8698$ & 99,2723 & $18.786 .167,4264$ & 7,3671 \\
\hline
\end{tabular}

Sumber: Hasil Perhitungan

1. Rugi-Rugi Daya Penyulang

Besarnya rugi-rugi daya yang terjadi pada penyulang dipengaruhi oleh panjang penyulang, karena panjang penyulang akan mempengaruhi nilai tahanan penyulang. Apabila penyulang semakin panjang maka nilai tahanan penyulang akan semakin besar, dan dengan semakin besarnya nilai tahanan penyulang maka rugi-rugi daya yang terjadi pada penyulang akan semakin besar. Dari Tabel 2 dapat dilihat bahwa penyulang yang paling panjang adalah Penyulang Cendana dengan panjang 16,505 km, dan mempunyai rugi-rugi daya yang paling besar yaitu 1,0085\%. Rugi-rugi daya yang terjadi pada penyulang juga dipengaruhi oleh arus yang mengalir. Tabel 2 menunjukkan bahwa Penyulang Sungkai mempunyai panjang penyulang yang lebih pendek dari pada Penyulang Tembesu tetapi rugi-rugi dayanya lebih besar dari pada Penyulang Tembesu. Hal tersebut disebabkan karena arus yang mengalir pada Penyulang Sungkai lebih besar dari pada arus yang mengalir pada Penyulang Tembesu. Tabel 4.18 juga menunjukkan bahwa dari empat penyulang pada Transformator $1,30 \mathrm{MVA}$ - $70 \mathrm{kV} / 20 \mathrm{kV}$ mempunyai rugi-rugi daya sebesar $136.699,5566 \mathrm{~W}$ atau $0,7277 \%$. Rugi-rugi daya yang terjadi pada jaringan distribusi tidak dapat dihilangkan karena adanya sifat material dari penghantar, yaitu adanya nilai tahanan pada penghantar yang dipakai. Besar nilai tahanan dipengaruhi oleh jenis penghantar, luas penampang dan panjang penghantar, dimana apabila nilai tahanan semakin besar maka rugi-rugi daya akan semakin besar. 


\section{Kapasitas Kebutuhan Daya Penyulang}

Kapasitas kebutuhan daya merupakan jumlah dari daya total dari sumber yang diinjeksikan ke beban dengan rugi-rugi daya total pada jaringan distribusi. Apabila rugi-rugi daya yang terjadi pada penyulang semakin besar, maka kapasitas kebutuhan daya akan semakin besar. Tabel 2 menunjukkan bahwa Penyulang Cendana mempunyai kapasitas kebutuhan daya yang paling besar, yaitu sebesar 2,9153\%. Tabel 2 juga menunjukkan bahwa empat penyulang tersebut mempunyai rugi-rugi daya sebesar $136.699,5566 \mathrm{~W}$ atau $0,7277 \%$, dan daya yang diserap oleh beban sebesar 18.649.467,8698 $\mathrm{W}$ atau 99,2723\%, sehingga kapasitas kebutuhan daya adalah sebesar 18.786.167,4264 W.

3. Evaluasi Ketersediaan Daya

Transformator 1 pada Gardu Induk Bungaran mempunyai kapasitas daya terpasang sebesar 30 MVA, dan apabila faktor daya untuk Transformator 1 diambil sama dengan setiap terminal beban pada penyulang yaitu $\cos \theta=0,85$, maka kapasitas terpasang Transformator 1 adalah sebesar 255.000.000 W. Dari hasil perhitungan dapat diketahui bahwa kapasitas kebutuhan daya dari empat penyulang adalah sebesar 18.786.167,4264 W atau 7,3671\% dari kapasitas daya terpasang. Jadi ketersediaan daya Transformator 1 pada Gardu Induk Bungaran masih mencukupi untuk melayani beban dari empat penyulang, karena hanya $7,3671 \%$ dari kapasitas daya terpasang daya yang diserap oleh beban dari empat penyulang.

\section{KESIMPULAN}

1. Rugi-rugi daya penyulang pada Transformator $1,30 \mathrm{MVA}-70 \mathrm{kV} / 20 \mathrm{kV}$ Gardu Induk Bungaran adalah sebagai berikut:

Rugi-rugi daya total dari empat penyulang pada Transformator 1, 30 MVA - 70 kV/20 kV adalah $136.699,5566 \mathrm{~W}$ atau $0,7277 \%$. Rugi-rugi daya yang terjadi pada penyulang dipengaruhi oleh panjang penyulang dan arus yang mengalir. Apabila penyulang semakin panjang dan arus yang mengalir semakin besar, maka rugi-rugi daya akan semakin besar.

2. Kapasitas kebutuhan daya total dari empat penyulang pada Transformator 1, 30 MVA - 70 $\mathrm{kV} / 20 \mathrm{kV}$ adalah $18.786 .167,4264 \mathrm{~W}$ atau 7,3671 \%. Kapasitas kebutuhan daya merupakan jumlah dari daya total dari sumber yang diinjeksikan ke beban dengan rugi-rugi daya total pada jaringan distribusi. Apabila rugi-rugi daya yang terjadi pada penyulang semakin besar, maka kapasitas kebutuhan daya akan semakin besar.

3. Transformator 1 pada Gardu Induk Bungaran mempunyai kapasitas daya terpasang sebesar 30 MVA atau 255.000.000 Watt. Sedangkan kapasitas kebutuhan daya total dari empat 
penyulang adalah 18.786.167,4264 W. Jadi ketersediaan daya Transformator 1 pada Gardu Induk Bungaran masih mencukupi untuk melayani beban dari empat penyulang, karena hanya $7,3671 \%$ dari kapasitas daya terpasang daya yang diserap oleh beban dari empat penyulang.

\section{DAFTAR PUSTAKA}

[1] Direktorat Jenderal Ketenagalistrikan (Ditjen Gatrik). 2016. Statistik Ketenagalistrikan 2015. Jakarta: Direktorat Jenderal Ketenagalistrikan Kementerian Energi Dan Sumber Daya Mineral.

[2] Gonen, Turan. 2008. Electrical Power Distribution System Engineering. Second Edition. New York: CRC Press Taylor \& Francis Group.

[3] Hutahuruk, TS. 1983. Jaringan Tegangan Menengah. Bandung: Badan Pelaksana Prokerma PLN-ITB.

[4] PT PLN. SPLN 72: 1987. Spesifikasi Desain Untuk Jaringan Tegangan Menengah Dan Jaringan Tegangan Rendah. Jakarta: PT PLN. 